\title{
Comment
}

\section{Compreensão sobre a Inclusão escolar: Realidade e Possibilidades}

\author{
Mirelly Moura Feijó de Figueiredo ${ }^{1}$
}

Resumo: Em sala de aula o docente trabalha com uma diversidade, em que cada sujeito apresenta suas particularidades. A inclusão de crianças com deficiências no ambiente escolar ainda é um desafio, já que muitas escolas ainda não apresentam uma estrutura física adequada, como também a qualificação docente, em que deixa a desejar o processo de inclusão. Este estudo tem como finalidade compreender a inclusão no ambiente escolar e seus desafios e possibilidades para vida do educando. Caracteriza-se por ser uma pesquisa de cunho bibliográfico, embasado em autores como: Kuenzer (2006), Saviani (2001), entre outros.

Palavras - Chave: Inclusão. Aluno. Aprendizagem.

\section{Understanding on School Inclusion: Reality and Possibilities}

\begin{abstract}
In the classroom the teacher works with diversity, in which each subject presents its peculiarities. The inclusion of children with disabilities in the school environment is still a challenge, since many schools still do not have a physical structure, but also the teaching qualification, in which leaves something to be desired the inclusion process. This study aims to understand the inclusion in the school environment and its challenges and possibilities for learner's life. It is characterized for being a bibliographical nature research, grounded in authors such as: Kuenzer (2006), Saviani (2001), among others.
\end{abstract}

Keywords: Inclusion. Student. Learning.

\section{Introdução}

A inclusão ao longo dos anos vem sendo estudada no campo da ciências humanas, em que o sujeito vem sendo compreendido diante de suas demandas tanto formativas como sociais. A escola desempenha papel importante no processo de formação educacional, e esta deve suprir as mais variadas necessidades, por meio da disponibilização de recursos materiais como humanos.

\footnotetext{
${ }^{1}$ Especialista em Psicopedagogia Institucional e Clínica pela Faculdade Cruzeiro do Sul. E-mail: mire123feijo@gmail.com
} 
A inclusão de pessoas com deficiências na educação básica é direito, mas ainda não encontra-se consolidada, já que muitas escolas não encontram-se preparadas para dar o devido suporte a este público. Gestores se recusam a incluir devido a ausência de uma estrutura organizacional adequada. Esta trata-se de ser uma realidade vivenciada por muitas escolas, em que não tem condições de dar o devido suporte a sujeitos com deficiências que exigem muita atenção e dedicação.

Assim, a inclusão não é um fator que envolve apenas a comunidade escolar para que esta seja desenvolvida com êxito, mas das instâncias federativas. Este estudo realiza uma abordagem acerca das conceituações que envolvem o termo deficiência, como também apresenta a escola no processo de inclusão, atuação docente e participação da família.

Este estudo tem como finalidade compreender a inclusão no ambiente escolar e seus desafios e possibilidades para vida do educando. Seu desenvolvimento foi pro meio da realização de pesquisas bibliográficas em diferentes fontes de pesquisa.

\section{Conceito de deficiência}

Muitos estereótipos envolve a educação inclusiva no país, em que estes necessitam ser superados. Mas, antes de realizar uma abordagem acerca dos progressos que ocorrem na educação inclusiva, é necessário compreender incialmente alguns aspectos presentes neste público, em especial a deficiência.

O dicionário Aurélio, aborda o termo deficiência como: "Insuficiência orgânica ou mental. Defeito que uma coisa tem ou perda que experimenta na sua quantidade, qualidade ou valor". Assim, as deficiências tanto podem ser congênitas ou adquiridas, comprometendo o desenvolvimento e relações do sujeito.

A inclusão veio a ser uma forma de incorporar as pessoas com deficiências na sociedade, já que estas durante muito tempo foram excluídas dos sistemas sociais, sofrendo resistência em sua inserção (SASSAKI, 2005).

A deficiência é uma temática constantemente discutida, em que foi realizado muitos movimentos por pesquisadores das ciências sociais e da saúde, com a finalidade de possibilitar 
melhores condições de vida para estes sujeitos. Por sua vez, há muitas barreiras, sejam arquitetônicas, como sociais (WASHINGTON GROUP, 2010).

A deficiência não pode ser vista apenas diante da ótica médica, como social, em que vem a ser relevante uma especificação das deficiências para que estas possam ser trabalhadas de forma adequada. Neste estudo a deficiência apresentada, envolve as limitações do sujeito, em que estas implicam de forma negativa em seu desenvolvimento.

\section{A escola versos a inclusão}

O termo incluir estar relacionado a envolver, a dar suporte a diversidade, para aqueles que durante muito tempo foram excluídos da sociedade possam se desenvolver, e ter acesso a seus direitos.

A inclusão no ambiente escolar visa permitir o desenvolvimento de pessoas que sofrem de algum tipo de deficiência, ou foram descriminadas pela sociedade, a inclusão busca favorecer condições de progresso para todos, sem distinção, bem como dar o devido suporte necessário, conforme as particularidades existentes.

Para Kuenzer (2006), com as mudanças que vem ocorrendo,

\footnotetext{
A escola é o lugar de aprender a interpretar o mundo para poder transformá-lo, a partir do domínio das categorias de método e de conteúdo que inspirem e que se transformem em práticas de emancipação humana em uma sociedade cada vez mais mediada pelo conhecimento.
}

A inclusão de pessoas com deficiências na sociedade é resultante de movimentos populares, voltados para superar o preconceito existente, como de ver estes sujeitos como pessoas que necessitam de atenção para que possam se desenvolver, como terem condições de serem autônomos, terem uma profissão, entre outros aspectos.

Para Freitas (2005), as atribuições que competem ao ambiente escolar envolve a realização de ações de combate à descriminação, possibilitando a inclusão de todos os sujeitos a serem atendidos, sendo este um espaço voltado para formação de sujeitos atuantes na sociedade. 
As escolas ainda não estão totalmente adaptadas para receber educandos com deficiências, ainda são poucos os recursos existentes, seja material, como profissional, já que nos cursos de formação docente não há uma intensificação acerca da inclusão, dos tipos de deficiências, ocorre apenas uma simples explanação, sem aprofundar acerca dos desafios e práticas pedagógicas a serem desenvolvidas.

Por sua vez, há muitos instrumentos normativos voltados para promoção da inclusão como o acesso a educação inclusiva, conforme ressalta Díaz et al (2009, p. 29),

\footnotetext{
- Constituição federal, Título VIII, artigos 208 e 227;

- Lei n. 7.853/89 - Dispõe sobre o apoio às pessoas com deficiência, sua integração social, assegurando o pleno exercício de seus direitos individuais e sociais;

- Lei n. 10.098/00 - Estabelece normas gerais e critérios básicos para promoção da acessibilidade das pessoas portadoras de deficiência ou com mobilidade reduzida e dá outras providências;

- Lei n. 10.172/01 - Aprova o Plano Nacional de Educação e estabelece objetivos e metas para a educação de pessoas com necessidades educacionais especiais;

- Decreto n. 5.296/04 - Regulamenta as Leis n. 10.048/00, que dá prioridade de atendimento às pessoas com deficiência, e 10.098/00, que estabelece normas gerais e critérios básicos para a promoção da acessibilidade das pessoas portadoras de deficiência ou com mobilidade reduzida, e dá outras providências.

- Lei n. 9.394/96 - Estabelece as Diretrizes e Bases da Educação Nacional;

- Decreto n. 3.289/99 - Regulamenta a Lei n. 7.853/89, que dispõe sobre a Política Nacional para a Integração da Pessoa Portadora de Deficiência, consolida as normas de proteção e dá outras providências;

- Portaria MEC n. 1.679/99 - Dispõe sobre os requisitos de acessibilidade a pessoas portadoras de deficiência para instruir processos de autorização e de reconhecimento de cursos e de credenciamento de instituições.
}

As normativas criadas voltadas para o acesso a educação e progresso social de pessoas com deficiência, buscam propiciar a este público oportunidade de mudanças, seja na construção de saberes, como na execução de atividades laborais.

\section{Qualificação docente na educação inclusiva}

É um desafio para o docente desenvolver suas atividades em sala de aula, com uma educando deficiente e este não ter conhecimentos acerca das necessidades deste sujeito, em que vem a desencadear a limitação no processo de aprendizagem do educando. 
Id on Line Revista Multidisciplinar e de Psicologia

Id on Line Multidisciplinary and Psycology Journal

Para Carvalho, (2004, p. 77):

\begin{abstract}
A Letra das leis, os textos teóricos e os discursos que proferimos asseguram os direitos, mas o que os garante são as efetivas ações, na medida em que se concretizam os dispositivos legais e todas as deliberações contidas nos textos de políticas públicas. Para tanto, mais que prever há que prover recursos de toda a ordem, permitindo que os direitos humanos sejam respeitados, de fato. Inúmeras são as providências políticas, administrativas e financeiras a serem tomadas, para que as escolas, sem discriminações de qualquer natureza, acolham a todas as crianças, independentemente de suas condições físicas, intelectuais, sociais, emocionais, lingüísticas ou outras...
\end{abstract}

A oferta de ensino necessita de atenção, perante o público de pessoas com deficiências. A qualificação docente é procedimento indispensável, para que tanto o educando como docente sejam beneficiados neste processo, visto que o docente fica em um estado de frustação quando não consegue suprir as demandas presentes em sala de aula. A educação inclusiva no país encontra-se em passos lentos, apesar das normativas instituídas.

Conforme a Resolução n. 2/2001 das Diretrizes Nacionais para a Educação Especial, muitos avanços ocorrem na oferta da educação voltada para pessoas com deficiências. Entre estes avanços encontra-se o art. $2^{\circ}$, em que aborda:

Os sistemas de ensino devem matricular todos os alunos, cabendo às escolas organizar-se para o atendimento aos educandos com necessidades educacionais especiais, assegurando as condições necessárias para a educação de qualidade para todos.

As deficiências comprometem o processo de desenvolvimento do sujeito acometido. Há vários tipos de deficiências, como por exemplo: deficiência mental, física, visual, auditivo, entre outros. Assim, o docente necessita compreender as limitações presentes em seu meio, para consecutivamente propor medidas que venham a contribuir para o desenvolvimento destes sujeitos.

Por sua vez, o docente não pode desempenhar sozinho o papel de formar, ou atuar no desenvolvimento do educando com deficiência, este requer a participação de toda comunidade escolar, participação de equipe multidisciplinar, como também da família, para que juntos possam superar os desafios presentes neste processo, e propiciar ao educando condições para o alcance de seu progresso social e intelectual (SAVIANI, 2001). 
Id on Line Revista Multidisciplinar e de Psicologia

Id on Line Multidisciplinary and Psycology Journal

\section{A família na escola}

A participação dos pais na inclusão dos filhos/educandos em sala de aula é indispensável, em que possibilita levar para o sujeito acometido com deficiência uma maior segurança, permitindo um melhor desenvolvimento.

De acordo com Nielsen (1999: 25) a participação da família é indispensável na vida do filho/educando com deficiência,

Para que as crianças tenham uma experiência educativa compensadora, os pais têm de ser também envolvidos no processo de inclusão. O professor, antes da colocação da criança na classe regular, deve convocar reuniões com os pais e deve, igualmente, convidá-los a visitar a classe em questão. É de primordial importância abrir portas de comunicação com os pais.

Quando a família está presente na vida dos filhos, as relações familiares como sociais ocorrem de forma significativa, pacificamente, envolvendo variados benéficos na vida de ambos, amenizando situações de conflitos e revolta.

Para McWilliam (et al, 2003: 13), "reconhecer e assumir os pontos fortes da família é apenas o primeiro passo a tomar no caso de uma abordagem optimista". É no ambiente familiar que o filho passa a desenvolver segurança acerca de suas interações no meio social, quando a família esconde da sociedade as limitações do filho, acaba limitando a sua capacidade de interação e superação desta limitação.

Por sua vez, o sujeito ter um tipo de deficiência não significa este estará condenado a morte imediata, ou não possa ter um trabalho, a sociedade encontra-se modernizada, as pessoas com deficiências estão ganhando sou espaço no mercado, mostrando seu potencial. Assim, as famílias devem ser conscientizadas sobre as possibilidades que estes sujeitos têm para se desenvolver. 
Id on Line Revista Multidisciplinar e de Psicologia

Id on Line Multidisciplinary and Psycology Journal

\section{Considerações Finais}

A inclusão ainda não foi totalmente incorporada no sistema educacional, ainda há muitos desafios a serem superados, em especial a organização do espaço físico, materiais didáticos, como a qualificação docente, em que todos estes aspectos quando não adequados comprometem o desenvolvimento do sujeito com deficiência. Assim, as instancias federativas, estaduais e municipais necessitam intervir, suprindo as demandas existentes na educação.

A partir do momento que a educação for vista como uma prioridade na sociedade brasileira, mudará o seu quadro de violência, de exclusão social, de fracasso econômico. Só por meio da educação é capaz de mudar as problemáticas presentes na sociedade, e sem esta apenas as coisas tendem a não progredir, ocorrendo um retrocesso socioeducacional.

Sim, a inclusão deve ser uma ação desenvolvida no ambiente escola, no entanto é relevante que os alunos sejam averiguados inicialmente diante de suas necessidades informacionais, já que alunos com um grau avançado de autismo, ou de outra deficiência neurológica avançada não pode estar em sala regular. Assim, se faz necessária uma maior atenção, para que possa ocorrer uma inclusão adequada, e que contribua para o desenvolvimento de todos.

\section{Referências}

CARVALHO, R. E. Educação Inclusiva: Com os Pingos nos “is”. Porto Alegre: Mediação, 2004.

DÍAZ, M. B.; GALVÃO, N.; MIRANDA, T. Educação inclusiva, deficiência e contexto social: questões contemporâneas. Salvador: EDUFBA, 2009.

KUENZER, A. Z. Conhecimento e competências no trabalho e na escola. 2006.

Disponível em: http://www.senac.br/informativo/BTS/282/boltec282a.htm Acesso em: 08 Dez 2016.

MCWILLIAM, P. J. Práticas de intervenção precoce centradas na família. In: MCWILLIAM, P.; WINTON, P.; CRAIS, E. (Eds.). Estratégias práticas para a intervenção precoce centrada na família. Porto: Porto Editora, 2003 
NIELSEN, L. B. Necessidades Educativas Especiais na Sala de Aula. Um Guia para Professores. Porto: Porto Editora, 1999.

SASSAKI, R. K. Terminologia sobre deficiência na era da inclusão. Revista Sentidos. Junho/2005.

Disponível em:

http://sentidos.uol.com.br/canais/materia.asp?codpag $=8322 \&$ codtipo $=8 \&$ subcat $=31 \&$ canal=visao. Acesso em 18 de novembro de 2016.

WASHINGTON GROUP ON DISABILITY STATISTICS. In: Statistical Commission fortyfirst session, 23-26 February 2010. New York, United Nations Economic and Social Council, 2010(E/CN.3/2010/20)(http://unstats.un.org/unsd/statcom/doc10/2010- 20-WashingtonGroupE.pdf, accessed 29 December 2010).

Como citar este artigo (Formato ABNT):

FIGUEIREDO, Mirelly M. F. Compreensão sobre a Inclusão Escolar: Realidade e Possibilidades. Id on Line Revista Multidisciplinar e de Psicologia, Fevereiro de 2017, vol.11, n.34, p.414-421. ISSN: 1981-1179.

Recebido: 20.02 .2017

Aceito: 23.02 .2017 